\title{
Fascia Research from a Clinician/Scientist's Perspective
}

Thomas W. Findley, MD, PhD

\author{
VA New Jersey Healthcare System, UMDNJ - New Jersey Medical School, East Orange, NJ, USA
}

\begin{abstract}
The upcoming Third International Fascia Research Congress will have much exciting information for the clinician, as well as for the clinical and basic science researcher. This paper provides a perspective from a clinician/scientist, including the fascial network of body-wide connections between and within individual cells, and sharing of loads between muscle and fascia. Basic studies of fibroblast cell shape show the impact of manual therapy, acupuncture, and yoga-like stretching at the cellular level. Advances in scientific equipment have made it possible to study a layer of hyaluronan fluid, which allows sliding between deep fascia and muscle. Collagen fibers within fascia affect both blood flow to muscles and lymphatic fluid flow.
\end{abstract}

KEYWORDS: fascia, conference, tensegrity, fibroblast, fluid flow, collagen

\section{INTRODUCTION}

Fascia research. What is all the buzz about? Why is there yet another international fascia congress in Vancouver, March 28-30, 2012, and why should we manual therapists attend? (Yes, I mean "we"). I am a physician in physical medicine and researcher who is crazy enough about research to have obtained my $\mathrm{PhD}$ during my residency program. As my wife will verify, I live, breathe, and dream research and, according to my mother, at age three I stood still for 45 minutes in the warmth of the winter sunlight streaming in through our dining room window, holding a jar of honey, proclaiming "I doing exerment [experiment]". The budding scientist in me was studying changes in the viscosity of a fluid with application of heat. I am still doing much the same thing 60 years later. However, I also am a manual therapist with a half-time clinical practice as a Certified Advanced Rolfer ${ }^{\mathrm{TM}}$.

I experienced Rolfing ${ }^{\circledR}$ Structural Integration in 1970, before attending medical school, and have carried the perspective on fascia developed by Dr Rolf throughout my career. Thirty years ago, I studied the clinical practice and scientific basis of muscle strengthening, exercise, stretching, heat, and other therapeutic modalities that are still used in my medical specialty today. Then our resident didactic lectures got to connective tissues. From the research standpoint, all we knew was that, if you heated a rat tail, you could stretch it. I eagerly absorbed the clinical experience of my teachers, learning procedures for dealing with connective tissues developed during the polio era; but my body knew there was more.

Fast-forward 20 years. As director of Research at Kessler Institute for Rehabilitation in New Jersey, I earned the trust of the hospital leaders, who were confident that I knew my material thoroughly and well, even though they also recognized that they had no real hope of understanding it. From that vantage point, I convinced them to sponsor a training program in structural integration at the hospital in 1991, for myself and other physical therapists. The therapists began using these techniques with the traditional rehabilitation patients with good results - even publishing them $^{(1)}$. I stayed in my research tower, except to use my bodywork training when faced with the challenge of getting Christopher Reeve off his ventilator (you can see some details in his remake of the Hitchcock thriller Rear Window). Even becoming a professor at UMDNJ School of Osteopathic Medicine did not dislodge me from my research perch. When I had the opportunity in 2000 for a sabbatical from my academic position, however, I did not write a book or do a new research project or visit a research laboratory. I chose to expand my horizons by setting up a clinical practice as a bodywork practitioner, and have maintained a half-time practice as an Advanced Rolfer ever since. In this editorial, I will join the ranks of my fellow manual therapy practitioners and give you my clinical perspective on the upcoming fascia research congress.

\section{DISCUSSION}

The fields of acupuncture, massage, structural integration, chiropractic, and osteopathy all present clinical hypotheses with fascia as a central theme. Yet many practitioners are unaware of the scientific basis for evaluating such hypotheses, and few know of the sophistication of current laboratory research equipment and methods. I will fill in some of these details, to give a flavor of what to expect at the next 
fascia congress. The hallmark of the fascia congress is interaction between clinicians and scientists, which is reflected in its theme: Fascia Research-What Do we Notice and What Do we Know-continuing the clinician-scientist dialogue. Particular effort is being made to incorporate clinical translation immediately following scientific presentations, and vice versa. We planned for time after each keynote to do this in Amsterdam in 2009, but then we received some incredibly exciting abstracts which were given those time slots instead. That was one reason, among many, to choose the Massage Therapists' Association of British Columbia to be the host - to make sure the science is translated into relevant concepts for the clinician.

I publicly admit that I was overwhelmed by the first congress, and similarly by the second. Both my clinical side and my research side had difficulty digesting all the material, so I watched the DVD recordings again, and again, and again. To be generous, I now understand perhaps half of what was presented. I went through probably 2000 recent papers on fascia to select a few outstanding ones for the 2012 program book, and it took me two hours to really understand one diagram from one paper selected — and this was after I had already used that diagram in a summary talk I gave on fascia research. The good news for you, my readers, is that I can now explain this material to you in ways that make sense to my clinical half. This editorial comes out of a four-hour workshop I recently gave at the AMTA national convention.

\section{It's All Connected}

We all know the children's song "the hip bone's connected to the thigh bone ...". Anatomy texts show these bony connections and two joint muscles such as the gastrocnemius, but they don't show the whole picture. I have a simple clinical demonstration of fascial continuity extending from the occiput to the calcaneus that I show medical students. It is quite simple. Sit in your chair with your knees bent and dorsiflex your ankle. Now stand up and do the same thing. It does not move as far-and we know why. The gastrocnemius extends across both the ankle and the knee. Now take that leg and with the knee straight, put it on the table in front of you. The foot moves less. Now bend your trunk forward. Even less motion. Next, drop your head. Now you can really feel tightness in your calf. This demonstrates just one simple fascial connection, the back-line, but the fascial connections throughout the body are far, far more intricate.

We find that muscles hardly ever transmit their full force directly via tendons into the skeleton, as is usually suggested by our textbook drawings. Rather, they distribute a large portion of their contractile forces onto fascial sheets. In some muscles (for example the Gluteus maximus), $85 \%$ of the fibers go to the distal fascia (in this case the Fascia lata) rather than to the theoretical muscle insertion. Muscles also transmit forces laterally to neighboring muscles; in some cases (measured in the rat leg), almost $50 \%$ of the muscle-generated force goes laterally rather than to the muscle tendon ${ }^{(2)}$. These forces go to synergistic partners, as well as cross the limb to antagonistic muscles. Thereby they stiffen not only the respective joint, but may even affect regions several joints away. The simple questions from musculoskeletal textbooks regarding "which muscles" are participating in a particular movement cannot be simply answered. Muscles are not separate individual functional units, no matter how much the textbook authors and your anatomy instructors want them to be. Rather, most motions are generated by many individual motor units, which are distributed over some portions of one muscle, plus other portions of other muscles. The tensional forces of these motor units are then transmitted to a complex network that converts them into the final body movement. While these pathways have been studied in the extremities where muscles cross one or two joints, there is little information on whether the same principles apply in the trunk, as well. However, the next fascia congress will show anatomic pictures of minute fascial strands between muscles in the neck which may well be myofascial connections. The program book for the 2009 congress shows tiny fibers extending from the muscle to pull open the nitric oxide receptors on the arterioles and, thus, immediately increase blood flow to that muscle ${ }^{(3)}$.

It rapidly gets very complicated. There are nerves in the motor cortex of the brain which directly communicate with muscles via a single synapse in the spinal cord. Fortunately, we do not have to use these often, or we would spend forever figuring out how to move. We have patterns of movement which we are born with, and others which we learn through repetition, and we generally rely on these automatic patterns to accomplish our daily activities. Remember how many months it took you to learn how to walk the first time? You may not, but your parents do. And we don't ordinarily forget these patterns, even after many years of disuse. How many of us have forgotten how to ride a bicycle? If you have a stroke which interferes with movement patterns, learning to walk the second time around goes quicker.

Many years of scientific studies have begun to probe the nature of movement, and the last fascia congress was held in a school of movement science. The individual motor units used for a particular movement depends on the force required-if more force is required, motor units with larger numbers of muscle fibers are used. If the motion requires less force, smaller units are used. Furthermore, there is a rotational system so that the motor units you use at any particular moment in time get a brief rest and other ones of similar size take over briefly ${ }^{(4)}$. Similarly, if you encounter unexpected resistance part way through performing a motion, more motor units are automatically brought to bear. This "sharing the load" function happens without our conscious awareness. 
At the 2007 Fascia Research Congress in Boston, Dr Gracovetsky showed us that in the lumbar spine the load is shared between muscles and fascia ${ }^{(5)}$. If the load were always on the muscles, they would fatigue; if it were always on the fascia, they would stretch out. Moving back and forth between the two allows the body to make use of the best characteristics of both. We find that fascial stiffness and elasticity also play a significant role in many ballistic movements of the human body. How far you can throw a stone, how high you can jump, and how long you can run depend not only on the contraction of your muscle fibers, but also to a large degree on how well the elastic recoil properties of your fascial network are supporting these movements. This is graphically illustrated by the double-amputee Oscar Pistorius, whose entrance into the 2008 summer Olympics was blocked because it was thought that his spring-like artificial legs gave him an unfair advantage over able bodied runners. It turns out they didn't - fascia is even better!

We are not just talking about fascial connections between muscles, bones, ligaments, and other large body structures. These fascial connections reach to the very interior of the cell, all the way to the nucleus. The scientific progress in documenting these connections has been truly amazing. As lead speaker in 2007, Dr Ingber showed us how the slightest touch on a cell surface with a micropipette caused the nucleus to immediately expand and begin DNA transcription ${ }^{(6)}$. The older models of the cell regarded it as a formless water balloon. Dr Ingber showed that, instead, the cell is built more like a tent with poles bearing compression and guy wires under tension, following the principles of tensegrity. He showed us that the microtubules in the cell are the equivalent of the tent poles, and the actomyosin filaments are the guy wires. The living cell is a mechanical structure with a force balance between compression-bearing microtubules and tension-bearing bundles of actomyosin filaments. The tent pegs are the integrin receptors. The cells are anchored to the extracellular matrix by clusters of integrin receptors, which connect extracellular proteins and filaments to intracellular filaments, the actin-associated molecules. These integrin receptors also serve to sense physical forces outside the cell and transmit that information through mechanical connections throughout the cell to the nucleus, as well as to multiple locations in the cell. This cytoskeleton provides both mechanical structure and direction to biochemical reactions within the cell. The cell can thus convert external mechanical signals into internal biochemical reactions ${ }^{(7)}$. In a similar fashion, development of the embryo is strongly influenced by the mechanical environment of the cell and is guided by this extra- and intracellular fascial network ${ }^{(8)}$.

Use of the experimental methods recently developed may allow us to explore the effects of externally applied forces that create repetitive stress disorders or assist in manually applied therapies. Many clinical therapies use externally applied forces based on empirical observations (some ancient), but rarely if ever are these treatments anchored in the biomechanical environment of the cell. Recent developments in medical diagnostic imaging may allow direct observation of this biomechanical context.

Dr Frederick Grinnell is doing some very important work at the cellular level, yet when he was invited to be a keynote speaker at the 2007 fascia congress he did not understand why his work was so important, despite his receiving Rolfing bodywork for many years. I had to explain the potential clinical meaning of his science and then he enthusiastically agreed. If we remain at the cellular level for a moment, we can look at the primary cell in fascia, the fibroblast. We find that fibroblasts synthesize, organize, and remodel collagen, depending on the tension between the cell and the extracellular matrix. In the 2007 Fascia Congress, Dr Grinnell showed so elegantly that at low tension from outside the cell, the fibroblast is in a resting state with low synthesis of collagen matrix ${ }^{(9)}$. When placed in a high tension matrix the fibroblasts increase their collagen synthesis and cell proliferation. The fibroblasts appear quite different in these two states. In low tension, they have a small cell body with dendritic extensions connected to other cells by gap junctions. In high tension matrix, the fibroblasts assume a larger cell body of lamellar shape. An individual fibroblast can change back and forth between these two cell morphologies. By looking in the microscope at the fibroblast, from the size of the cell body one can infer the tension placed on the cell: the higher the tension, the larger the cell body. This change in cell body size affords the opportunity for measuring at the cellular level the effects of therapies designed to change fascial tension.

Each fibroblast can remodel nearby collagen matrix, and this local remodeling can spread throughout the matrix to result in large scale matrix contraction. By exerting traction on the matrix, the fibroblast can either cause motion of the collagen or movement of the fibroblast through the matrix ${ }^{(10)}$. Fibroblasts produce and degrade matrix proteins, with an indirect effect on matrix stiffness. They can also differentiate into myofibroblasts, which can contract and increase matrix tension. By changing shape, the fibroblast can affect stiffness and viscosity of connective tissue within minutes, consistent with the mechanotransduction model of microtubule network expansion and actomyosin generated tension proposed by Ingber ${ }^{(7)}$. The fibroblast may also remodel cell matrix contacts in the direction of tissue stretch to reduce tension ${ }^{(11)}$. Does the fibroblast just respond to the mechanical forces around it, or is it a primary force for directing growth and adaptation? Either way, it is a key player in the fascial orchestra, and perhaps it is the conductor.

\section{And Therapies Actually Do Something}

Using these new techniques for imaging the fibroblast, at the first congress in 2007 Drs Standley ${ }^{(12)}$ and 
Langevin ${ }^{(13)}$ showed the cellular effects of manual therapy, acupuncture, and yoga-like stretching. And they continued with new findings from their research, which they presented at the second Fascia Congress in Amsterdam in $2009^{(14,15)}$. Connective tissue actively regulates matrix tension in response to stretch as a normal, dynamic physiological process. Understanding how cells respond to forces can lead to potential new treatments and refinements on existing ones.

And there's more ... several new areas will be presented in the 2012 fascia congress. Some of this research is not new, it is more than ten years old, yet we are just appreciating its application.

The deep fascia is a highly vascular structure with a superficial and a deep layer, each with an independent rich vascular network of capillaries, venules, arterioles, and lymphatic channels. The presence of mast cells in deep fascia suggests a protective role similar to other connective tissues. The deep layer has few elastin fibers but does have myofibroblasts, suggesting contractile ability. Any active contraction would need to be controlled by a nerve supply and, indeed, one finds myelinated and unmyelinated nerve axons and Schwann cells in these deep fascial layers. The deep fascia is not just a tough barrier structure of collagen and elastin, but is a metabolically active vascular layer which provides gliding and protective functions ${ }^{(16)}$. Deep fascia has parallel longitudinal collagen bundles and rudimentary elastic laminae, giving it both high tensile strength and elasticity. At the junction between the deep fascia and the muscle, without any special secretory cells, the fascia is able to maintain a lubricating layer of hyaluronic acid (hyaluronan) which, like a hydraulic fluid, allows sliding between the fascia and neighboring muscle. However, when the epimysium is disrupted in surgery, overlying fascia does not remain distinct and does not create a gliding layer over the scar ${ }^{(17)}$. More recent findings show that while hyaluronic acid is a lubricant, breakdown products of this large molecule are themselves tissue irritants ${ }^{(18)}$, and fragments from collagen, elastin, and laminins in the extracellular matrix also modulate activities of inflammatory cells ${ }^{(19)}$.

This layer of hyaluronan is 100-200 microns thick. The architecture of the fascia allows continuity of nerves, blood, and lymph vessels between the sliding tissues. With trauma to the muscle, the overlying fascia no longer produces the sliding layer of hyaluronan. Restoring this natural sliding mechanism becomes the next task for the manual therapist.

I was a car mechanic before I went to medical school, and learned that my hands could detect valve clearances with an accuracy of one thousandth of an inch (that equals 25 microns). I would lie on my back, reach up around the engine on the old air-cooled VWs, pop off the valve cover, and wiggle the rocker arm to check the valve clearances. From time to time, I would go through the effort of squeezing in a feeler gauge to check what my fingers were telling me. To put this in perspective, a red blood cell is 8 microns in diameter and a sheet of paper is about 75 microns. Most of us can tell the difference between 75 and 150 microns, for example when we turn the page on a magazine and accidentally get two at a time. I am convinced that feedback from the clinician's hands can guide manual therapy, although we don't yet have the bodywork equivalent of the mechanics feeler gauge to check our perceptions. The newer musculoskeletal ultrasound imaging machines are beginning to have sufficient resolution to see a hyaluronic acid layer of 100-200 microns (MRI resolution is about 300 microns). I have tested the ultrasound machine I use in my clinical practice. It can measure thickness with an accuracy of almost 50 microns in my research projects when I insert objects into mozzarella cheese, but I can't consistently see the hyaluronic acid layer in humans yet. My hands are still better.

\section{But the Most Exciting Aspect of the Next Fascia Congress Is ...}

In planning the 2012 congress, the scientific committee had a hunch that fluid flow was an important concept to address. As we sought keynote speakers in this area, we learned how right we were. Dynamic mechanical stresses have long been recognized as important in the maintenance of supporting structures such as bone and muscle. Less well recognized is the need for stresses and pressure gradients to maintain function in all living tissues. In soft tissues, interstitial flow is primarily driven by plasma leaving the blood capillaries and that pressure gradient, in turn, is affected by large movements of the skeletal system and smaller motion from arterial pulsation, respiration, and organ motion. This slow interstitial flow can have a direct mechanical effect on cells, as well as transporting proteins and other components of the biochemical environment. However, increased interstitial flow stimulates fibroblasts to differentiate into myofibroblasts, and increase production of collagen and other factors associated with fibrosis ${ }^{(20)}$.

Collagen displays piezoelectric properties; this was invoked 50 years ago from studies of dried bone as a mechanism to explain the remodeling of bone in response to stress. However, when investigators began studying wet bone, they found the remodeling was primarily directed by streaming potentials from the movement of fluid through the bone canaliculi connecting with Haversian canals ${ }^{(21)}$, rather than by piezoelectric properties. Fluid flow thus appears again as an important bioregulator.

Until I spent two hours figuring out what the 2012 keynote speaker Dr. Rolf Reed meant by one diagram in his recent paper ${ }^{(22)}$, I myself did not fully appreciate how important this fluid flow is. The loose connective tissue surrounding the organs and muscles has four main components: 1) a network of collagen fibers which is the primary three-dimensional scaffold for the blood vessels; 2) elastin microfibrils; 3) ground substance including hyaluronan; and 4) interstitial 
fluid. This tissue is not static and its properties can be rapidly modified. In humans, the extracellular fluid volume is $15 \mathrm{~L}$, with normal blood plasma volume of $3 \mathrm{~L}$, and 6-10 L passes through the lymph system each day with resulting turnover of extracellular fluid every 48 hours. There is substantial flow of fluid through our tissues every day, every hour. I always thought that fluid leaked out of the blood vessels and passed through lymph channels until it returned to the venous system. As it turns out, we find as much complexity in the fluid as we do in the muscular and fascial system. Here is where the manual therapist comes in.

Histological studies show that fascia consists of cells (mostly fibroblasts), collagen fibers, and a large amount of amorphous material called ground substance. In mechanics terms, it is similar to fiberglass cloth and resin used in auto body repair, except that both the cloth and the resin can change properties depending on the applied loads. My focus at this point is not on the strength and material properties of fascia, but rather on its regulation of fluid flow. Rather than being a passive filter, the extracellular ground substance directly affects fluid flow. Reed ${ }^{(22)}$ notes that the interstitial matrix contains osmotically active compounds, particularly hyaluronans, which will swell when given free access to fluid. Extracellular cellular matrix fibers restrain this swelling when they are actively tensed by connective tissue cells through $\beta_{1}$ integrin mediated contraction. This restrains the fluid retaining capacity of the ground substance which is normally underhydrated.

Thus the extracellular ground substance is normally restrained from absorbing fluid by tension on collagen fibers which restrain the substance's ability to swell as it draws in fluid. It sits there, like a sponge tied up with string. With trauma to tissue, the fluid flow out of the capillary can increase by a hundredfold within minutes. This is not because it is leaking out of the capillary (that only changes 1-2 times). It is because the ground substance actively draws the fluid out. Thus the loose connective tissues are neither static nor passive, and within minutes can change their physical characteristics to affect fluid flow.

Therapies designed to locally increase edema, such as Chinese cupping, may increase the adaptability of the fluid flow adjustment systems by temporarily increasing fluid flow. Therapies to reduce lymphedema must take into account the tissue changes which take place with a prolonged decrease in interstitial flow, including the increased tissue compliance or "overstretching" of the interstitial matrix. All organs, muscles, and body structures must be viewed in the context of the surrounding connective tissues and distant blood and lymphatic fluid flow; specific pathology cannot be fully understood or treated without taking those tissues into account. In recognition of the regulation of body function by mechanical forces, I suggest we begin to use the term "mechanotherapy," coined by Khan ${ }^{(23)}$ for physical therapy, to guide both our scientific exploration and our clinical applications.
My clinical experience in medicine also sheds some light on the controversy in manual therapy regarding which treatment is best. I spent almost ten years in the clinical practice of pediatric rehabilitation and saw many children with cerebral palsy who were born with limitations in their ability to perform motor movements. We all are born with certain movement patterns wired into our spinal cord and our brain. As we grow we learn to control and use these patterns, but not be dominated by them. Children with cerebral palsy cannot do this as well as normal children. There are a number of physical therapy treatment interventions for cerebral palsy: a treatment named after the inventor (Bobath), or the technique (proprioceptive neuromuscular facilitation), are two examples. Research has identified underlying neurological movement patterns (eg, Babinski, long spinal reflex, crossed extensor, flexor withdrawal). Yet in the end, the choice of therapies remains primarily according to the preference of the treating therapist, as there is little hard evidence for choosing one over another. Does this sound familiar to selecting treatments in manual therapy? Guidance for developing studies to evaluate manual therapies will be presented in a keynote address by Dr. Karen Sherman at the upcoming fascia congress.

\section{CONCLUSION}

I could go on with what we know and might learn, but these give you a sampling of some of the things to expect at the next fascia congress. Multiple other smaller congresses addressing fascia are now appearing in the United States, Europe, and Asia, and keynote speakers from the earlier fascia congresses have injected fascial concepts into many other scientific meetings. However, in my view the International Fascia Congress remains the leader in the advancement of our understanding of fascia. The Third congress will boast seven new keynote speakers supplemented by more than 100 abstracts submitted by scientists and clinicians. I hope to see you there for another fabulous conference! You can fully expect the same level of excitement as captured by Science magazine's report on the first congress ${ }^{(24)}$.

If you want to prepare ahead of time, you can order the program books and DVDs from the previous fascia congresses at http://www.fasciacongress. org/2009/dvd-book-purchase-pub.htm. I will also present a full-day workshop on January 14, 2012 at the Center for Natural Wellness School of Massage Therapy in Albany, NY, designed to prepare clinicians to attend the next fascia congress. (http://www. cnwsmt.com/redpines.php/286/Fascia-and-Musclein-Myofascial-Pain-Fascia-Research-Provides-aNew-Window-into-Management/). To encourage this preparation, the Massage Therapists' of British Columbia and the Ida P. Rolf Research Foundation have teamed up to provide attendees at this preparatory workshop with a \$200 discount on their attendance 
at the Fascia Congress. We are also planning similar workshops in San Francisco and in Vancouver prior to the next congress. These will be posted at http://www. rolfresearchfoundation.org/events. Full details of the preconference workshops and the conference registration are available at www.fasciacongress.org.

\section{ACKNOWLEDGMENTS}

The Center for Natural Wellness School of Massage Therapy is thanked for its generous donation of a major portion of the workshop registrations to the Ida P. Rolf Research Foundation to support fascia research and education.

\section{CONFLICT OF INTEREST NOTIFICATION}

Dr. Findley is Executive Director of the Fascia Research Congress and the Ida P. Rolf Research Foundation. He receives limited travel reimbursement for expenses and no salary.

\section{COPYRIGHT}

Published under the CreativeCommons AttributionNonCommercial-NoDerivs 3.0 License.

\section{REFERENCES}

1. Deutsch JE, Derr LL, Judd P, et al. Treatment of chronic pain through the use of structural integration (Rolfing). Orthop Phys Ther Clin N Am. 2000;9(3):411-428.

2. Maas H, Sandercock TG. Force transmission between synergistic skeletal muscles through connective tissue linkages [online]. J Biomed Biotechnol. 2010;2010:575672.**

3. Hocking DC, Titus PA, Sumagin R, et al. Extracellular matrix fibronectin mechanically couples skeletal muscle contraction with local vasodilation. In: Huijing PA, Hollander P, Findley TW, Schleip R, editors. Fascia Research II: Basic Science and Implications for Conventional and Complementary Health Care. Munchen: Elsevier Urban \& Fischer; 2009. p. 129-137.

4 Bawa P, Murnaghan C. Motor unit rotation in a variety of human muscles. J Neurophysiol. 2009;102(4):2265-2272.**

5 Gracovetsky S. Is the lumbodorsal fascia necessary? [DVD Recording]. Boston MA: First International Fascia Research Congress; 2007. Available from: http://fasciacongress.org/2007/

6 Ingber D. Tensegrity and mechanotransduction [DVD Recording]. Boston MA: First International Fascia Research Congress; 2007. Available from: http://fasciacongress.org/2007/

7 Ingber DE. From cellular mechanotransduction to biologically inspired engineering: 2009 Pritzker Award Lecture, BMES Annual Meeting Oct. 10, 2009. Ann Biomed Eng. 2010;38(3):1148-1161.

8 Mammoto T, Ingber DE. Mechanical control of tissue and organ development. Development. 2010;137(9):1407-1420.**
9 Grinnell F. Fibroblast mechanics in three-dimensional collagen matrices. [DVD Recording]. Boston MA: First International Fascia Research Congress; 2007. Available from: http:// fasciacongress.org/2007/

10. Grinnell F. Fibroblast mechanics in three-dimensional collagen matrices. J Bodyw Mov Ther. 2008;12(3):191-193.**

11. Langevin HM, Bouffard NA, Fox JR, et al. Fibroblast cytoskeletal remodeling contributes to connective tissue tension. J Cell Physiol. 2011;226(5):1166-1175.

12. Standley PR. Biomechanical strain regulation of human fibroblast cytokine expression. [DVD Recording]. Boston MA: First International Fascia Research Congress; 2007. Available from: http://fasciacongress.org/2007/

13. Langevin HM. Fibroblast cytoskeletal response to tissue stretch and acupuncture. [DVD Recording]. Boston MA: First International Fascia Research Congress; 2007. Available from: http:// fasciacongress.org/2007/

14. Meltzer KR, Cao TV, Schad JF, et al. In vitro modeling of repetitive motion injury and myofascial release. J Bodyw Mov Ther. 2010;14(2):162-171.**

15. Langevin HM. Fibroblast cytoskeletal remodeling contributes to viscoelastic response of arealoar connective tissue under uniaxial tension. [DVD Recording]. Boston MA: Second International Fascia Research Congress; 2009. Available from: http://fasciacongress.org/2009/

16. Bhattacharya V, Barooah P, Nag T, et al. Detail microscopic analysis of deep fascia of lower limb and its surgical implication. Ind J Plast Surg. 2010;43(2):135-140.**

17. McCombe D, Brown T, Slavin J, et al. The histochemical structure of the deep fascia and its structural response to surgery. J Hand Surg Br. 2001;26(2):89-97.

18. Stern R, Asari AA, Sugahara KN. Hyaluronan fragments: an information rich system. Eur J Cell Biol. 2006;85(8):699-715.

19. Adair-Kirk TL, Senior RM. Fragments of extracellular matrix as mediators of inflammation. Int J Biochem Cell Biol. 2008;40(6-7):1101-1110.**

20. Rutkowski JM, Swartz MA. A driving force for change: interstitial flow as a morphoregulator. Trends Cell Biol. 2007;17(1):44-50.

21. Ahn AC, Grodzinsky AJ. Relevance of collagen piezoelectricity to "Wolff's Law": a critical review. Med Eng Phys. 2009;31(7):733-741.**

22. Reed RK, Liden A, Rubin K. Edema and fluid dynamics in connective tissue remodelling. $J$ Mol Cell Cardiol. 2010;48(3):518-523.**

23. Khan KM, Scott A. Mechanotherapy: how physical therapists' prescription of exercise promotes tissue repair. Br J Sports Med. 2009;43(4):247-252.**

24. Grimm D. Cell biology meets rolfing. Science. 2007;318: 1234-1235.

Corresponding author: Thomas W. Findley, MD PhD, VA New Jersey Healthcare System UMDNJ New Jersey Medical School, 385 Tremont Ave., East Orange, NJ 07018 USA

E-mail: Thomas.findley@va.gov

** These are available without charge from PubMed: http://www. ncbi.nlm.nih.gov/pubmed 